\title{
Optimization of the evaluation indexes of coalbed methane gas extraction
}

\author{
Akash Talapatra \\ Department of Petroleum and Mining Engineering, Chittagong University of Engineering and Technology, Chittagong, BANGLADESH \\ Corresponding Author: e-mail: talapatraakash@gmail.com
}

\begin{abstract}
The extraction procedure of coalbed methane is usually different from conventional type of gas extraction. Generally, the CBM extraction procedure is completed within two approaches. First one is drilling on the surface for heading downward through the ground \& second one is extracting through the existed underground coal mines. For making the CBM extraction an economic viable, well optimization development should be implemented with carefully. So, an evaluative technique called 'Unit Technical Cost' briefly known as UTC can be one of the better way to evaluate the well optimization development. This optimization technique is evaluated practically based on the two major coal basins of china, known as 'Qinshui basin \& Ordos Eastern Margin basin'. The well completion \& simulation process can be examined by the parameters that are used in this technique. This paper is tried to give a new research on CBM well development based on using the UTC method for making decision criteria to calculate the optimization level. The calculation is done using the detailed properties of UTC in the well development by establishing the process theory. In this research, the production profiles are evaluated for building up the engineering \& geologic parameters where the product price, operating cost \& project investment is evaluated for finding the economic parameters. This is found from the optimized results that a horizontal well should be optimized for its economic feasibility in the Qinshui Basin where directional well optimization is better for Ordos Eastern Margin Basin.
\end{abstract}

Keywords: Well optimization, well completion, unit technical cost, technical evaluation, evaluation index

DOI: http://dx.doi.org/10.4314/ijest.v11i3.2

\section{Introduction}

Actually Coalbed Methane (CBM) is known as an unconventional gas produced from unconventional form of coal seams or deposits during coalification process. The methane is the main elemental gas of this coal seam gas. Not only that, but also the methane gas is found both in an adsorbed form on the surface of the coal matrix \& in freed state between coal pores [Ministry of land, 2003; Rogers, 1994]. In previous days, this methane gas was uplifted from coal seams suddenly \& considered as a harmful \& trouble situations during coal extraction process. But the situation has changed day by day. Now this CBM gas is likely to play a vital role in the field of unconventional sources of sustainable energy. Among the most coal mining developed countries, the USA acquired the success in developing the extraction methods of coalbed methane in the 1990s.

The CBM gas extraction approaches are not only differentiated from conventional oil \& gas, but also from other types of unconventional oil \& gas, for example, tight sand gas or oil, shale gas or oil etc. For the development of CBM has been, the approaches have been sectionalized into two steps. First one is the surface drilling that is heading downward through ground surface \& second one is the underground excavation through the existing coal mine. The underground excavation needs additional drilling those are done with different equipment \& methods from surface drilling. The materials are used with more carefully in these sites to increase gas recovery \& create proper water drainage system. Recently, the drilling on surface is more preferable for the CBM extraction all over the world. The development approaching of the surface drilling is optimized for well pumping units (Wu, 2000; Ni et al., 2007). The well types are specified mainly with surface drilling in various directions or sites such as horizontal or vertical wells, multiple or single lateral wells, U figured wells, etc. Among them, multiple horizontal wells \& 
directional wells are the most recommended drilling well types for CBM extraction. Selection of well type can affect in the decision of planning \& design of CBM production (Zhao,1999; Xian et al., 2005).

It is very important to economize \& effect the development of CBM extraction with implementing well-optimization approaches. Here economic states quality \& effective well optimization are evaluated by using the techniques of Unit technical Cost (UTC) method. This method makes the CBM development optimization in very simply \& accurately. The advantage of this technique is finding out the exact parameters that are carried on some formulas. Then, the evaluated parameters are optimized for used in simulation process that can provide the accurate numerical solutions to select the best well drilling type method. Because, the later planning \& designs for CBM production from reservoirs will be very helpful to get surety about the decision of using horizontal or directional type of well drilling in excavation underground coal seams. Finally, the possibility of producing a large amount CBM gas will be ensured from the reservoir without any type of systematic loss or economic loss.

\section{Literature Review}

It is estimated from year 2000s that the coalbed methane's annual production has been increased over 60 billion cubic meters that have accounted for approximately $10 \%$ of the total natural gas production. After showing this project developed in the USA, Canada and Australia also adopted some advanced methods after cognizing the commercial value of the coalbed methane consistently. In course of time, they are trying to find their own developed technology helping with the past methods that will be suited for their country (Luo et al., 2008; Sun \& Huang, 1998; Sun, 2005; Qin, 1996). After got inspiring from other countries, China has also started to accept some on-time steps for coalbed methane production as they have large amount of CBM resources. To develop the commercial scaling of production, China is running some explorations \& testings on CBM method recently (Dai et al., 2011; Dai et al., 2010). Figure 1 shows a scheme of the total growth production of coalbed methane in China since 2003s to 2015s (Hangyu \& Huang, 2018).

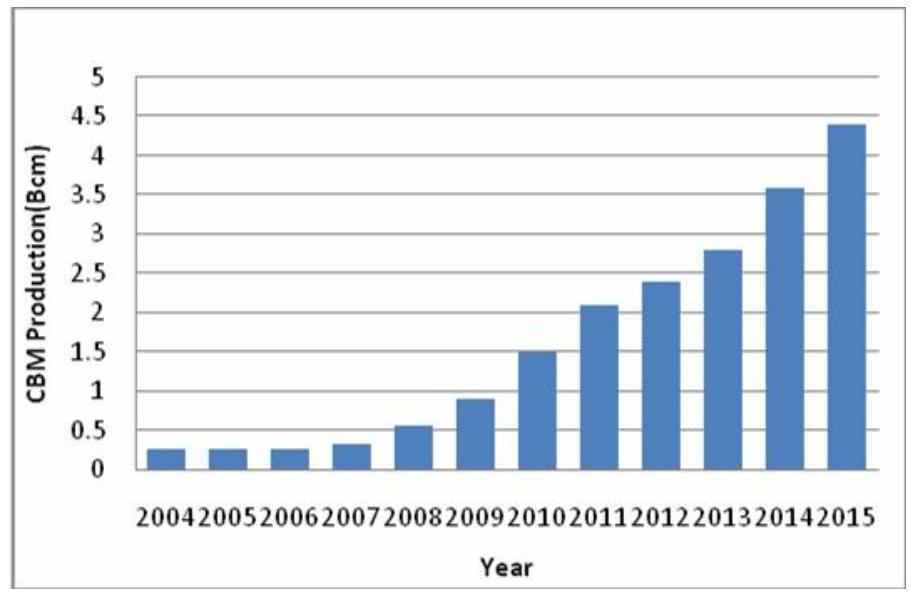

Figure 1. Annual production of Coalbed methane in China(Cubic meters).

\subsection{Technical evaluation method}

There are about 13 geological parameters which are needed essentially in well optimization, stimulation \& CBM drilling in North America identified by a renowned geologist Sunil Ramaswamy (2007). To optimize the combination of specific geological parameters implemented in CBM basins associated with the analyzing of corresponding well completion \& stimulation. Not only that, but also the some supported technical methods for well optimization are built all over the world (Huang et al., 2004). Based on the determination of permeability, the planning \& designing will be executed for further processing of CBM well completion (Ramaswamy, 2007). The recommendations for the selection of specific well type are also depended on the advantages \& the disadvantages characteristics of the CBM development. Some geological \& technological aspects are used for increasing the reliable strategies of CBM development.

In this method, some technical key parameters of well optimization test are analyzed for industrial practices in CBM development. But sometime this can't be beneficial for the decision makers working on the well optimizing test of the CBM development to take decision for gaining the highest benefits when the price of oil is low enough. Because, there is remained no other scope in this method which makes the well type optimization test an economically viable under current low prices of oil.

\subsection{Economic evaluation method}

Based on horizontal \& vertical strategies, Wangtao et al. (2009) used a method named Discount Cash Flow (DCA) method for evaluating the virtual economic durability of full multiple-lateral horizontal \& vertical wells development for the same control area without realizing the takeover of production. The significance \& differences of economic viability of these two technologies are 
compared \& synthesized for developing the CBM method in China (Ian,2010). Again Yang Yongguo et al. stated some technical evaluation methods for specific geological conditions after analyzing some indices \& parameters in applying on the CBM project (Luo et al.,2009; Kuuskraa \& Boyer, 1993; Yang, 2001). It requires creation of some virtual development in the various well drilling or completion tests so that it goes thoroughly with economic performances. These approaches are associated with the engineering data, collection of investment etc. to compare the economic appraisement with the project economic requirements \& then it continues the well drilling \& well completion approaches based on the estimated results. The results that found from the used economic \& technical parameters are not exact enough as the condition has changed gradually from the early to last stage of the project. Sometimes the carrying out result of the parameters shows poor capability for the CBM development. To increase the utility of the CBM development, it is necessary to add a strong operability with a fast \& exact method for the decision makers working for well optimization.

\section{Method}

\subsection{Definition}

The Unit Technical Cost (UTC) sometimes can be introduced by another formal name as Long Run Marginal Cost (LRMC). It is expressed as a ratio of total cost specially capital expenditure of the total life of a project to the anticipated outputs from the project. From this extensive economical index, it helps the investors to yield decisions for the project. The price of the products involve with the project does not affect this UTC (Yang et al., 2001). UTC gives a relationship between economic cushion \& estimated actual product price that indicates the cost of the products to produce \& develop. It is a well known fact that the gas \& oil production projects have the characteristics of long operational duration, construction, high risk occurrence, essentiality of large amount of capital investment etc. Recently, some large oil companies such as BP, Shell etc. have subsequently introduced UTC for applying in the decision of making investment to the evaluation system of gas \& oil projects.

A CBM well is generally considered as an independent approximately unit for its unconventional type of characteristics. Here UTC can provide more complete information about the total cost (CAPEX \& OPEX) of the output product unit during the project life. The difference between the conventional cost \& UTC index is it requires the value of time for the total cost \& future estimation. So, UTC behaves as a short-time index through discount in the real cost of the project. If the project is accepted as economically viable, then an evaluation index can be made to compare the product prices. In the intervening period, based on discount of cash flow method some consistent project evaluation indexes like Net Present Value (NPV), Internal Rate of Return (IRR) etc. are used.

\subsection{Modeling}

The Unit Technical Cost is sometime discounted or undiscounted if considers it theoretically. But the discounted UTC is more appropriate \& accurate according to the determination of the practical cost of the gas \& oil industries. Yearly costs should be required for determining the discounted UTC where the same discount rate is used for calculating the Net Present Value after discounting the production into the present value. In a CBM well, the UTC is nearly equal to the functioning cost of the CBM well $\&$ the discounted present value of investment on construction for future production of the project. Appointed formulas for specific calculation are provided as follows:

$$
\begin{gathered}
U T C=\frac{P V_{1}+P V_{C}}{P V_{P D}} \\
P V_{1}=\sum_{t=1}^{x} \frac{I_{t}}{(1+t)^{t}} \\
P V_{C}=\sum_{t=1}^{n} \frac{C_{t}}{(1+i)^{t}} \\
P V_{P D}=\sum_{t=1}^{n} \frac{P D_{t}}{(1+i)^{t}}
\end{gathered}
$$

Here, the following representations are valid

$\mathrm{n} \quad$ Sum of the construction \& operation period for a CBM well

$\mathrm{x} \quad$ Integrated construction year of a CBM well

I Acceptable discount rate for the well

$I_{t} \quad$ Spending amount of investment behind the construction in year

$\mathrm{C}_{\mathrm{t}} \quad$ Amount of operational cost in year

$\mathrm{PD}_{\mathrm{t}} \quad$ Production of CBM well in year $\mathrm{t}$

$\mathrm{PV}_{1}, \mathrm{PV}_{\mathrm{C}} \& \mathrm{PV}_{\mathrm{D}}$ Discounted values of investment, cost \& production of the through the economic life of the well 
In this case, it is supposed that the production in the CBM well is directly related to the operating cost. Moreover, the unit operation cost denoted by Unit $\mathrm{C}$ will remain be identical through the whole production season where the annual operational cost is equal to the product of annual production and Unit $\mathrm{C}$.

Now, the above mentioned formula (1) can be simplified as given below:

$$
U T C=\frac{P V_{1}}{P V_{P D}}+\text { UnitC }
$$

Consequently, the Evaluation Index (EI) can be exhibited as follows:

$$
E I=P-U n i t C
$$

Here, $\mathrm{P}=\mathrm{CBM}$ 's unit sale price

\subsection{Intrinsic unity between $N P V \& E I$}

In the gas \& oil industry, a new method known as discounted cash flow method is commonly obtained in the most cases. So, three main evaluation exponents Internal Rate of Return (IRR), Net Present Value (NPV) \& Payback Period (PP) are indexed for this method. Among them, the broadly used index is NPV that can be attained by deducting the present value of outflow periodic cash from the present value of inflow periodic cash. The average weighted cost of the invested capital that is defined as the discounted rate, also known as minimum acceptable rate of return (Mian, 2010). There is still a consistency between EI \& NPV based on the evaluation result of economic viability of the project, though they have substantial difference by definition. The calculation formula of NPV is given as follows:

$$
N P V=\sum_{t=1}^{n} \frac{P_{t} x P D_{t}}{(1+i)^{t}}-\left[\sum_{t=1}^{x} \frac{I_{t}}{(1+i)^{t}}+\sum_{t=1}^{n} \frac{C_{t}}{(1+i)^{t}}\right]
$$

Through the entire evaluation period, the price of the product is retained constant at $\mathrm{P}$. Then $\mathrm{P}_{\mathrm{t}}$ will be equal to $\mathrm{P}$. After that, the both sides of the formula (7) are divided by the projected output of discount value synchronously as follows:

$$
\frac{N P V}{\sum_{t=1}^{n} \frac{P D_{t}}{(1+i)^{t}}}=P-\frac{\left[\sum_{t=1}^{x} \frac{I_{t}}{(1+i)^{t}}+\sum_{t=1}^{n} \frac{C_{t}}{(1+i)^{t}}\right]}{\sum_{t=1}^{n} \frac{P D_{t}}{(1+i)^{t}}}=P-U T C
$$

By which

$$
E I=\frac{N P V}{\sum_{t=1}^{n} \frac{P D_{t}}{(1+i)^{t}}}=\frac{N P V}{P V_{P D}}
$$

Since, the projected output of the discount value can't be equal or less than zero then EI \& NPV can have the possibility of being negative \& positive attributes. One more thing can be observed from this discount cash flow method that there is a greater consistency between UTC based evaluation index \& commonly used NPV based evaluation index.

\subsection{Characteristics \& decision-devising process}

The difference between the total unit cost of project output \& the product price is referred as the UTC-based evaluation index (EI). This evaluation index (EI) is more instinctive, practical, effective \& expedient for the better CBM optimized type of well \& economic feasibility compared with evaluation index that is based on the conventional discount cash flow method. Still there is an internal consistency between the UTC \& discounted cash flow method indices IRR \& NPV if it considers the main theoretical designation. Not only that, but also this method has reached to an economic conclusion that is more intuitive \& efficient in the case of operability. It can be assumed that the both type of wells, horizontal \& directional wells are equally practicable, if the large base of CBM resource is remained adequate there. The principles \& procedures shown from the perspective of economic feasibility for the making of designing $\&$ decision processes are give below:

(1) The prices of the products are estimated from the anticipation of different output plans under various types of well according to the pilot, engineering, geology \& analog data.

(2) From this information, the UTC of horizontal \& directional wells is calculated.

(3) Then, the several values of EI are examined CBM development feasibility. The larger the values of EI in a well, the better the economic it is recommended for the feasibility of CBM development under current economic \& technical conditions. It is assumed as a potential type of well if it has higher evaluation index for directional \& horizontal wells $(\mathrm{EID} \searrow 0$ \&IH $\searrow$ ). But if the well has lower EI values (EID $\unlhd$ \& EIH $\unlhd$ ), the well can't be selected for the optimal CBM development as the production is not economically feasible under this condition. 


\section{Application}

China is one of the world's largest CBM resource countries where only Canada \& Russia are ahead of it. There is about 36.8 trillion cubic meters of CBM resources that are buried under less than $2000 \mathrm{~m}$ (Mu et al., 2015). There are nine main basins of CBM resources existing in china, among which two main basins are Qinshui Basin \& Ordos Eastern Margin Basin that have approximately $3.8 \& 9.9$ trillion cubic meters of CBM resources respectively. An estimation stated in year 2014, shows that the production of CBM resources from the Qinshui Basin \& Ordos Eastern Margin Basin accounted for nearly to $94.2 \%$ of the total production China with using an approach of surface development. The demonstration of the CBM resources from these two basins has been reached already into the industrial state level after increasing the extraction \& production in a large scale (Sun et al., 2005). Since these two basins have a large amount of CBM resources, so both types of well, horizontal \& directional wells are technically feasible. In this case, the UTC method can be used for evaluating the economic inconstancy of the two types of well \& their variety. Now this UTC method is accepted for optimizing \& modeling theplans of the two types of well for the above mentioned two basins.

\subsection{Qinshui basin}

The area of this coal-bearing basin is about 2.3 square kilometers which is located at the Shanxi Province in the southeastern part. At the end of 2014, the estimated results of the proven reserves at this site were higher than 450 billion cubic meters, in which the capacity of cumulative annual production was higher than 4 billion cubic meters. It is expected that the gradual increases of this available reserves can reach up to 900 billion cubic meters \& the additional construction has been run continuously to increase the capacity of annual production up to 14-15 billion cubic meters. These factors along with a five year periodic plan have made this basin a key area for the production of CBM reserves. Not only that, but also the capacity of the CBM production of this area is economical. The production profiles of the typical Qinshui basin are shown in Figure2 according to the horizontal \& directional wells (Lei et al., 2015; Liu et al., 2013) \& the evaluation parameters of that basin are provided in Table 1.

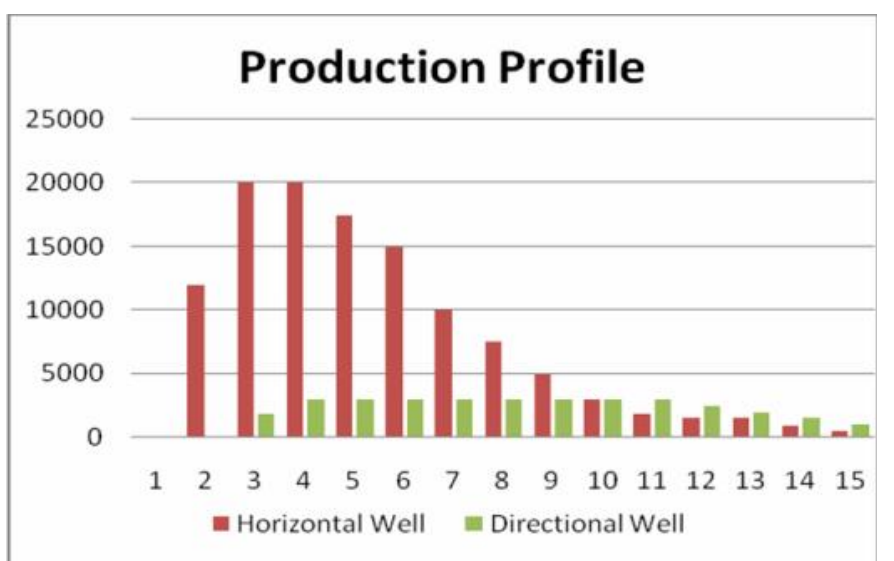

Figure 2: Comparative production profile of typical directional \& horizontal wells in Qinshui Basin. Data are compiled from open source.

Table 1. Comparative production profile of typical directional \& horizontal wells in Qinshui Basin.

Parameter Unit Value

Daily Production Rate ( Stable in Horizontal Well) $\quad \mathrm{m}^{3} / \mathrm{day} \quad 20000$

Daily Production Rate ( Stable in Directional Well) $\quad \mathrm{m}^{3} /$ day 3000

Investment in Horizontal Well $\quad 10000$ Yuan $\quad 220$

Investment in Directional Well $\quad 10000$ Yuan 1200

Price $\quad$ Yuan $/ \mathrm{m}^{3} \quad 1.00$

Discount Rate in Percentage (\%) $\quad 10 \%$

Note: Data are compiled from open source

\subsection{Ordos eastern margin basin}

Like the previous Qinshui Basin, this Ordos Eastern Margin Basin also has 2.5 square kilometers of coal-bearing area which is located across the three states are Shaanxi, Shanxi \& Inner Mongolia. This basin is also considered as other key area for the CBM production in China, in where the anticipation of production plan is being implemented for a period of 5 years. At the end of 2014, the proven reserves for the CBM production are nearly to 160 billion cubic meters along with an approximation of 650 million cubic meters annual production. The amount of cumulative products obtained in 2014 was more than 1.6 billion cubic meters. It is assumed that the cumulative capacity of production would be reached up to 10-12 billion cubic meters along with accumulative 
reserves of 525-550 billion cubic meters in the final stage. The production profile of this typical basin is shown in Figure 3 according to the horizontal \& directional wells \& the evaluation parameters of this basin are provided in Table2.

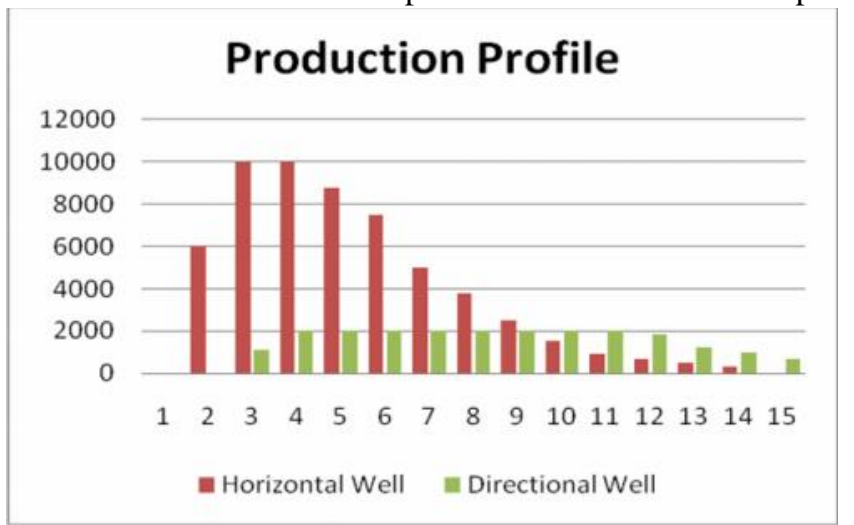

Figure 3: Comparative production profile of typical directional \& horizontal wells in the Ordos Eastern Margin Basin. Data are compiled from open source.

Table 2:Well-types evaluation parameters in the Ordos Eastern Margin Basin.

\begin{tabular}{lll}
\hline \multicolumn{1}{c}{ Parameter } & Unit & Value \\
\hline Daily Production Rate ( Stable in Horizontal Well) & $\mathrm{m}^{3} /$ day & 10000 \\
Daily Production Rate ( Stable in Directional Well) & $\mathrm{m}^{3} /$ day & 2000 \\
Investment in Horizontal Well & 10000 Yuan & 250 \\
Investment in Directional Well & 10000 Yuan & 1300 \\
Price & Yuan/ $\mathrm{m}^{3}$ & 1.50 \\
Discount Rate & in Percentage $(\%)$ & $10 \%$ \\
\hline
\end{tabular}

Note: Data are compiled from open source.

\subsection{Evaluation index calculation and analysis}

The model \& data which are shown above used for determining the EI under several types of well from the Qinshui\& Ordos Eastern Margin Basins respectively. The obtained results are demonstrated in Table 3.

Table 3: Evaluation results of well-type optimization for the Qinshui\& Ordos Eastern Margin Basins.

\begin{tabular}{llll}
\hline Parameter & Unit & \multicolumn{1}{c}{ Value } \\
\cline { 3 - 4 } & & Qinshui Basin & Ordos Eastern Margin Basin \\
\hline UTC in Horizontal Well & Yuan $/ \mathrm{m}^{3}$ & 0.661 & 1.359 \\
UTC in Directional Well & Yuan $/ \mathrm{m}^{3}$ & 0.810 & 1.192 \\
EI in Horizontal Well & Yuan $/ \mathrm{m}^{3}$ & 0.339 & 0.141 \\
EI in Directional Well & Yuan $/ \mathrm{m}^{3}$ & 0.190 & 0.308 \\
Selective Decision & & Horizontal Well & Directional Well \\
\hline
\end{tabular}

Note: Data are compiled from open source.

After observing the results accurately found from the Qinshui \& Ordos Eastern Margin Basins in horizontal \& directional wells, It is came to the conclusion that the production of CBM resources from these basins are economically feasible under several economic \& technical conditions. Because the values of UTC in the horizontal \& directional wells are greater than zero that shows in the above mentioned evaluation results. Since the value of UTC in the directional well is greater than the value of UTC in the horizontal well \& the value of EI in the directional well is less than the value of EI in the horizontal well, so it is assumed that the development of CBM resources would be beneficial in the horizontal well types under the uniform level of price from the directional well types. On the contrary, for the Ordos Eastern Margin Basin, the development of CBM resources would be economical \& beneficial in the directional well types under same level of price than horizontal well types. Because the value of UTC in the directional well is lower than horizontal well where the value of EI in the directional well is larger than the value of EIin the horizontal well, though both of these wells have the values of UTC higher than zero like the previous basin. So, the summary of the UTC \& EI results determined from the both types of basin are used conveniently \& technically to choose the preferred types of well for the CBM development under different reserves. These results are also used for helping in the efficient decision-making process of the $\mathrm{CBM}$ resources development in China.

\section{Conclusion}


Here optimization of the development of the several directional \& horizontal well is considered as the main issue of the CBM development to make it both reasonable \& effective under specific economical \& technical conditions. But if the methods that are maintained in traditional system e.g. AHP \& Technical Evaluation methods are economically \& technically insufficient, though they also take the some engineering \& geological factors like UTC method. The operational capability of the traditional evaluation method based on some project economical aspects is not so effective. This paper is tried to give a new research on CBM well development based on using the UTC method for making decision criteria to calculate the optimization level. The calculation is done using the detailed properties of UTC in the well development by establishing the process theory. In this research, the production profiles are evaluated for building up the engineering $\&$ geologic parameters where the product price, operating cost $\&$ project investment are evaluated for finding the economic parameters. The conventional evaluation method is viewed slightly same with this method when the operational standpoint is considered. These evaluated methods are designed mainly for the above mentioned two basins of China. This is found from the optimized results that horizontal well should be optimized for its economic feasibility in the Qinshui Basin where directional well optimization is better for Ordos Eastern Margin Basin.

The guidelines for optimizing these types of well development in these two basins have not been achieved yet in commercial scale. Still the implications of these two well types are fully going on these basins. However, the time to time updated optimization $\&$ evaluation of these methods are important to give surety of the CBM development of these two basins. However, not only these two basins, but also there are also few basins situated in China that are not able yet to select the drilling method \& evaluate the economic feasibility about the production of coalbed methane. If their evaluation parameters can be determine by this unit technical method, then it would be more convenient to select the type of well that would be the suitable type of well for getting the best economic profit. In upcoming future, these studies on unit technical method can contribute in the field of extracting the coalbed methane gas from the coal seams, even from the basins that have low amount adsorbed methane gas.

\section{Acknowledgement}

Great thanks are presented to a regional director of the of China coal mining plant for providing me some information to write this paper.

\section{References}

Dai, Y., Luo, D., Xia, L. 2010. Cash flow analysis assesses China's CBM viability. Oil and Gas Journal, Vol. 184, pp. 45-49.

Dai, Y., Luo, D., Xia, L. 2011. Economic evaluation based policy analysis for coalbed methane industry in China. Energy, Vol. 36, pp. 360-368.

Hangyu, L., Huang S. 2018. China's coalbed methane development: A review of the challenges \& opportunities in subsurface \& surface engineering. Journal of Petroleum Science and Engineering, Vol. 166, pp. 621-635.

Huang, H., Lu, M., Shen, R. 2004. CBM pinnate horizontal directional drilling technology research. Nat. Gas Ind., Vol. 24, pp. 76-78. (In Chinese)

Ian Palmer. 2010. Coalbed methane completions: A world view. International Journal of Coal Geology, Vol. 82, pp. 184-195.

Kuuskraa, V., Boyer, C. Economic and parametric analysis of coalbed methane. (1993). In Hydrocarbons from Coal; The American Association of Petroleum Geologists: Tulsa, OK, USA, pp. 373-394.

Lei, H., Sun, F., Chen, Y. 2015. Some thoughts on development of CBM industry in China. International Oil Economics, Vol. 23, pp. 14-18. (In Chinese)

Liu, S., Yuan, W., Zhang, X. 2013. Research on CBM well gas production curve characteristics and recovery rate in Panzhuang Block. J. Coal., 38, 164-167. (In Chinese)

Luo, D.C., Chu, W., Wu, X. 2009. Analysis on economy of CBM drilling technology. Petroleum Exploration and Development, Vol. 36, pp. 403-407. (In Chinese)

Luo, D., Wu, X., Zhang, B., Chu, W. 2008. Feasibility Study on Coalbed Methane Production in China; China University of Petroleum: Beijng, China. (In Chinese)

Mian, M.A. 2010. Project Economics and Decision Analysis. Available online: https://books.google.com/books?hl=en\&lr=\&id=eSpPFiMSsoUC\&oi=fnd\&pg=PR11\&dq=Project+Economics+and+Decision+ Analysis,+Volume+1+Deterministic+Models.+Pennwell:+2010\&ots=xpzQTCzYHj\&sig=qth2KGQRsBrIH_CpAxPsW2nOc6 $\mathrm{M} \# \mathrm{v}=$ onepage $\& \mathrm{q} \& \mathrm{f}=\mathrm{false}($ assess on 18 August 2016).

Ministry of Land and Resources. (2003). National Standard Coal Bed Gas Resources/Reserves Specification (DZT0216); Geological Publishing House: Beijing, China. (In Chinese)

Mu, F., Zhong, W., Zhao, X., Chen, Y., Zhu, J., Wang, B. 2015. Thinking on Chinese CBM industry development strategy. Natural Gas Industry B, Vol. 35, pp. 110-116. (In Chinese)

Ni, X., Wang, Y., Jie, M., Yan, B. 2007. Study on coal bed methane extraction mode. Coal Mine Saf., 3, 45-48. (In Chinese)

Qin, Y. 1996. Evaluation and Production Technology of Coalbed Methane Reservoir; China University of Mining and Technology Press: Beijing, China. (In Chinese) 
Rogers, R. 1994. Coalbed Methane: Principles and Practices; Prentice Hall: London, UK.

Ramaswamy, S. 2007. Selection of Best Drilling, Completion and Stimulation Methods for Coalbed Methane Reservoirs. Master's Thesis, Texas A \& M University, Texas, TX, USA.

Sun, M., Huang, S. 1998. Handbook of Coalbed Methane Development and Utilization; China Coal Industry Press: Beijing, China. (In Chinese)

Sun, W. 2005. China Coalbed Methane Basin; Geological Publishing House: Beijing, China.

Sun, W., Chen, S., Chen, X., Wang, S., Fu, X. 2005. Chinese CBM basin geological characteristics and resource prospect. Oil Nat. Gas Geol., Vol. 26, pp.141-146. (In Chinese)

Wu, P. 2000. Theory and Practice of Coalbed Methane Development; Geological Industry Press: Beijing, China. (In Chinese)

Xian, B., Gao, J., Li, A., Zhao, Q., Cao, W. (2005). Analysis on the mechanism and application of coal bed gas directional plume in horizontal well production. Nat. Gas Ind., Vol. 25, pp. 114-116. (In Chinese)

Yang, Y. 2001. Research on the Theory and Method of Economic Evaluation of Coalbed Methane Project; China University of Mining and Technology Press: Xuzhou, China. (In Chinese)

Yang, Y., Qin, Y., Zhang, D. 2001. Application of analytic hierarchy process (AHP) and its application in the economic evaluation of coal bed gas projects. Coal Geol. Explor., Vol. 29, pp. 19-21. (In Chinese)

Zhao, Q. 1999. Coalbed Methane Geology and Exploration Technology; Petroleum Industry Press: Beijing, China. (In Chinese)

\section{Biographical notes}

Akash Talapatra is of the Department of Petroleum and Mining Engineering, CUET, Chittagong, Bangladesh.

Received March 2019

Accepted April 2019

Final acceptance in revised form April 2019 